\title{
RONGGENG DI MINANGKABAU
}

\author{
Eka Meigalia
}

\begin{abstract}
Abstrak
Kata "ronggeng" merupakan kata yang identik dengan salah satu seni tradisi di Jawa. Akan tetapi, tradisi ronggeng ini juga dapat ditemukan di daerah lainnya di luar Jawa, salah satunya di Pasaman. Tradisi ini unik karena hidup dan tumbuh di daerah Pasaman, yaitu daerah khas dengan percampuran budaya dari berbagai etnis. Hal itu tercermin pula dalam tradisi ronggeng yang ada di sana, yang dikenal dengan sebutan Ronggeng Pasaman. Tulisan ini memaparkan tradisi Ronggeng Pasaman dilihat dari konsep hibriditas. Hibriditas adalah konsep melihat bahwa setiap proses budaya mengandung percampuran dan interaksi lintas batas. Hibriditas dari tradisi ini pertama terlihat dari namanya yang mengambil nama dari tradisi ronggeng di Jawa. Kedua dari pelaku tradisi yang keseluruhannya adalah laki-laki karena mengadopsi tradisi di Minangkabau yang melarang perempuantampil.Ketiga,mengambiltradisiberpantundiMelayusertaalatmusik pengiring (seperti biola, akordion, dan sebagainya). Keempat, bahasanya adalah bahasa Minang dengan logat Pasaman dengan beberapa kosakata Mandailing.
\end{abstract}

Kata kunci: Ronggeng Pasaman, hibriditas, Jawa, Minangkabau, Mandailing.

\begin{abstract}
The word "ronggeng "is a word that is synonymous with one of the traditional arts in Java. However, this ronggeng tradition can also be found in other areas outside of Java , one of them in Pasaman. This tradition is unique in that it lives and grows in areas Pasaman, which is typical of the area with the mixing of cultures ofvarious ethnic groups . This was reflected also in the tradition ronggeng there, known as Ronggeng Pasaman. This paper describes the tradition Ronggeng Pasaman seen from the concept of hybridity. Concept of hybridity is seen that each process contains a mixture of cultural and cross-border interactions. Hybridity of this tradition the first look of his name which takes its name from the tradition ronggeng in Java. Both of the perpetrators of the whole tradition is because men are adopting the tradition in Minangkabau prohibit women to appear. Third, take berpantun tradition in Malay as well as other musical instruments ( such as violin, accordion, and so on). Fourth, the language is the language Minang accent with several vocabulary Mandailing Pasaman .
\end{abstract}

Keywords : Ronggeng Pasaman, hybridity, Javanese, Minangkabau, Mandailing . 


\section{Latar Belakang}

Ketika mendengar istilah ronggeng, yang terpikir pertama kali adalah salah satu seni tradisi dari Jawa yang berhubungan dengan ritus kesuburan. Namun tradisi ronggeng tersebut ternyata juga ditemukan di daerah Minangkabau yang jelas-jelas adat-istiadat serta tradisinya berbeda dengan Jawa. Yang lebih menarik, ronggeng di sini telah diakui sebagai salah satu seni tradisi Minangkabau, khususnya sebagai sebuah tradisi lisan dari daerah Minangkabau, tepatnya dari daerah Pasaman.

Baik ronggeng maupun Pasaman ternyata keduanya memiliki cerita dan hal-hal yang unik seputar isu multikultur. Pasaman sebagai salah satu wilayah administratif di Sumatera Barat berdasarkan hasil survey dihuni oleh tiga etnis dominan, yaitu Minangkabau, Mandailing, dan Jawa (www.depdagri.go.id). Ketiga etnis dominan yang mendiami daerah Pasaman tersebut sudah tinggal hingga beberapa generasi di daerah tersebut. Masing-masing etnis memberi pengaruh terhadap budaya, tradisi, serta bahasa di sana.

Berbicara mengenai interaksi dan hidup berdampingan antara etnis Minang, Jawa, dan Mandailing di Pasaman tidak dapat dilepaskan dari permasalahan multikultur. Multikultur sebagai suatu bentuk kehidupan sosial yang terdiri dari beberapa budaya yang hidup berdampingan antara lain juga terkait dengan isu identitas, migrasi (diaspora), serta hibriditas. Hal ini akan sengat menarik salah satunya dengan mengambil daerah Pasaman sebagai objek kajiannya.

Lebih spesifik lagi, interaksi serta hidup berdampingan antara tiga etnis tersebut di Pasaman telah menghasilkan salah satu produk budaya yang dapat dikatakan sebagai produk budaya yang hibrid, yaitu tradisi ronggeng yang oleh masyarakat setempat disebut ronggeng pasaman. Di dalamnya dapat ditemukan beragam unsur budaya dari etnis Minang, Jawa, dan juga Mandailing. Hal ini akan penulis bahas lebih lanjut dalam tulisan berikut ini.

\section{Konsep Hibriditas}

Manusia adalah makhluk yang selalu berpindah baik secara sukarela maupun karena paksaan. Dari zaman prasejarah telah disebutkan bahwa manusia selalu mencari daerah baru jika di daerah tempatnya berada sebelumnya mulai kekurangan bahan pangan atau dilanda bencana. Hal itu juga terjadi hingga saat ini. Alasannya juga berhubungan dengan mencari mata pencaharian yang lebih baik, mencari pendidikan yang lebih baik yang nantinya juga terkait dengan mata pencarian, serta masalah lainnya seperti peperangan atau bencana alam. Lebih menarik lagi, beberapa etnis memiliki tradisi berpindah itu dengan istilah merantau seperti yang terdapat di dalam suku Minangkabau. Sejak dulunya, seorang laki-laki Minang sudah terbiasa dengan tradisi merantau karena selain dapat memperbaiki nasibnya sendiri, dia juga dapat menaikkan pamor keluarganya di dalam masyarakat.

Untuk perpindahan atau migrasi penduduk ini, dalam kajian lintas budaya sering digunakan istilah 'diaspora'. Menurut Georgiou (dalam Budianta, 2007:4), diaspora dapat diartikan sebagai komunitas yang terdiri dari orang-orang yang 
pernah mengalami migrasi dan mereka yang dilahirkan dan dibersarkan di Negara pemukiman baru. Diaspora mengimplikasikan suatu kaitan dengan etnisitas atau budaya tertentu dari tempat asal, yang menjadi (salah satu) acuan penting, bukan saja bagi generasi yang lahir di tempat pemukiman baru. Konsep ini juga mengandung pengertian bahwa acuan terhadap budaya asal tetap relevan, walau besar kemungkinannya secara terus menerus diproses dan berubah sesuai dinamika budaya yang terjadi di tempat pemukiman baru. Konsep ini juga mengacu pada pengalaman kesejarahan yang khas dari komunitas tersebut yang membedakannya dari komunitas budaya lainnya.

Dari konsep tersebut dapat dilihat bahwa etnis yang telah mendiami wilayah baru tersebut tetap terkait serta menjadikan budaya dari tempat asalnya sebagai salah satu acuan yang penting bagi kehidupan mereka di tempat yang baru. Budaya dari tempat asal mereka tersebut memang sangat mungkin terus diproses dan berubah sesuai dengan dinamika budaya yang terjadi di tempat pemukiman yang baru. Hal itu kemudian terkait pula dengan istilah 'hibriditas'. Hibriditas pada dasarnya mengacu pada identitas rasial atau etnik yang muncul dari perkawinan campur, atau produk budaya (karya seni, tradisi, gaya hidup, busana, bahasa, dan sebagainya) yang menunjukkan percampuran genre maupun campuran berbagai unsur budaya yang berbeda-beda. Konsep hibriditas ini juga dapat menunjukkan bahwa setiap proses budaya mengandung percampuran dan interaksi lintas batas. Tidak ada suatu kebudayaan yang sepenuhnya asli dan murni (Hall dalam Budianta, 2007:9).

Dalam tradisi ronggeng pasaman yang merupakan produk budaya dari masyarakat Pasaman secara kasat mata telah mencerminkan bagaimana percampuran beberapa kebudayaan itu di dalamnya. Salah satunya dapa dilihat dari istilah ronggeng itu sendiri yang memang tidak terdapat dalam kosakata bahasa Minang atau pun Mandailing. Kata ronggeng hanya terdapat dalam kosakata bahasa Jawa. Lebih lanjut bagaimana percampuran budaya yang terdapat dalam tradisi ronggeng pasaman akan tergambar dalam pembahasan berikut.

\section{Pasaman}

Pasaman merupakan salah satu kabupaten yang terdapat di provinsi Sumatera Barat. Kabupaten yang beribukota Lubuksikaping ini secara geografis (administratif) berbatasan di sebelah utara dengan Kabupaten Mandaling Natal, Provinsi Sumatera Utara. Karena wilayahnya yang terletak di wilayah perbatasan provinsi Sumatera Barat dengan Sumatera Utara ini, penduduknya pun tidak hanya berasal dari suku Minangkabau, namun juga suku Mandailing dari Sumatera Utara.

Selain kedua etnis di atas, di wilayah ini juga banyak suku Jawa yang juga telah berketurunan sejak zaman pemerintahan Belanda di daerah ini. Pada masa itu, wilayah Pasaman yang subur dimanfaatkan oleh pemerintah Belanda sebagai salah satu daerah penghasil komoditi karet. Kebun karet yang hingga saat ini masih banyak terdapat di wilayah Pasaman ini dulunya membutuhkan tenaga kerja yang banyak. Untuk itu, Belanda mendatangkan pekerja-pekerja dari Jawa untuk 
bekerja di daerah Pasaman ini. Akhirnya pekerja-pekerja itu hingga sekarang telah berketurunan hingga dua atau tiga generasi di wilayah ini.

Nama Pasaman sebenarnya diambil dari nama sebuah gunung yang terdapat di daerah ini, yaitu gunung Pasaman. Selain itu juga terdapat sebuah sungai yang diberi nama Batang Pasaman. Kata Pasaman sendiri berasal dari kata pasamoan yang berarti "kesepakatan dan atau kesamaan pendapat". Hal ini juga terkait dengan keragaman etnis yang mendiami wilayah ini, yaitu Minangkabau, Mandailing dan Jawa, sehingga kesepakatan dan kesamaan pendapat itu adalah hal yang mereka utamakan agar tidak terjadi perselisihan antar etnis tersebut.

Keberadaan etnis Mandailing di wilayah Pasaman ini juga terkait dengan pembagian wilayah keresidenan pada zaman pemerintahan Belanda di Indonesia. Pada awalnya, wilayah Pasaman ini termasuk pada wilayah kekuasaan kerajaan Mandalaholing yang berpusat di Mandailing dan kekuasaannya meluas sampai ke kawasan Pasaman (Lubis, 2008). Karena pengaruh kekuasaan dari kerajaan Mandalaholing itu meluas hingga ke Pasaman, orang-orang Mandailing pun telah ada di wilayah Pasaman sejak lama.

Sementara itu, dalam tambo Minangkabau juga dijelaskan bahwa wilayah kekuasaan kerajaan Minangkabau berbatasan di sebelah utara dengan Tapanuli, Sumatera Utara (Samad, 2002: 102). Artinya, wilayah Pasaman yang dalam sejarah kerajaan Mandailing diakui termasuk wilayah kekuasaan kerajaan tersebut juga telah diakui termasuk ke wilayah kekuasaan kerajaan Minangkabau. Meskipun begitu, dalam pembagian wilayah budaya Minangkabau, Pasaman bukanlah tempat sumber dan pusat budaya Minangkabau yang dikenal sebagai wilayah darek ${ }^{1}$, namun hanyalah wilayah yang disebut wilayah rantau, yaitu daerah perluasan kerajaan Minangkabau sehingga budaya dan tradisi di daerah ini tidak persis sama dengan daerah pusat budaya Minangkabau. Artinya, masyarakat Minang yang terdapat diwilayah ini juga dianggap orang rantau dari daerah darek yang menjadi pusat budaya Minangkabau.

Dari penjelasan di atas dapat disimpulkan bahwa daerah Pasaman telah mendapat pengaruh dari dua kerajaan tersebut sehingga budaya dan tradisi yang terdapat di sana tidak sepenuhnya seperti tradisi Minangkabau dan juga tidak sepenuhnya seperti tradisi orang Mandailing di Tapanuli Selatan. Meskipun begitu, dalam kehidupan sehari-hari masyarakat Pasaman tetap terlihat bahwa mereka tetap lebih banyak mengacu pada adat-istiadat serta tradisi Minangkabau. Salah satunya terlihat dari tata cara perkawinan yang tetap memakai tata cara Minang (tradisi meminang, pakaian adat, serta tradisi mengikuti garis keturunan ibu) meskipun juga terlihat ada pengaruh tradisi etnis lainnya.

Wilayah Pasaman ini kemudian berdasarkan kebijakan pemerintah Belanda dimasukkan ke wilayah yang disebut Residentie vant Sumatra Westkust. Setelah era kemerdekaan wilayah Residentie vant Sumatra Westkust itu dikenal sebagai provinsi

1 Wilayah yang dianggap sebagai sumber dan pusat adat Minangkabau, dan terletak di dataran tinggi. Wilayah ini terbagi lagi atas tiga wilayah yang disebut luhak, yaitu Luhak Tanah Datar, Luhak Agam, dan Luhak Limo Puluh Koto. Kota-kota yang termasuk ke dalam tiga luhak ini antara lain Bukittinggi, Payakumbuh, Lubuk Basung, dan Batu Sangka. 
Sumatera Barat yang wilayahnya berbatasan dengan Sumatera Utara di sebelah utara, Jambi dan Riau di sebelah selatan, Samudera Hindia di sebelah barat, dan Riau di sebelah timur (Samad, 2002: 103).

Daerah Pasaman yang telah menjadi salah satu kabupaten di Provinsi Sumatera Barat akhirnya memiliki ragam budaya dari dua etnis yang berbeda ini. Hal tersebut salah satunya dapat dilihat dari dua bahasa yang digunakan di wilayah ini, yaitu bahasa Mandailing dan bahasa Minangkabau (Amir, 2007:128). Beberapa kosakata Mandailing yang ditemui dalam bahasa sehari-hari masyarakat Pasaman yaitu mulak yang artinya 'pulang', bagas yang artinya 'kampung', dan mancit yang berarti 'sakit'. Mulak, bagas, dan mancit dalam kosakata Minang tidak ditemui. Kata yang digunakan adalah pulang, kampuang, dan sakik.

Sementara itu, etnis Jawa yang juga mendiami wilayah ini tidak terlalu banyak mendominasi kehidupan sosial budaya masyarakat setempat. Bahasa Jawa tidak menjadi salah satu bahasa ibu di wilayah ini. Begitu juga adat istiadat di wilayah ini tidak begitu banyak dipengaruhi oleh adat istiadat dari Jawa. Namun begitu, salah satu tradisi yang terdapat dalam masyarakat Jawa, yaitu ronggeng ternyata telah menjadi salah satu seni tradisi di daerah Pasaman yang kemudian telah diakuik sebagai salah satu tradisi lisan Minangkabau.

\section{Ronggeng Pasaman}

Meskipun bahasa atau pun tradisi dari etnis Jawa tidak banyak mempengaruhi kehidupan masyarakat di wilayah Pasaman ini, tapi yang menarik adalah salah satu tradisi lisan di daerah ini yang jelas-jelas dari namanya saja mengingatkan kita pada satu seni tradisi dari Jawa, yaitu ronggeng. Di daerah Pasaman ini, ronggeng tersebut biasa disebut ronggeng pasaman untuk membedakannya dengan istilah ronggeng yang terdapat di Jawa.

Di Jawa, ronggeng merupakan salah satu tradisi yang berhubungan dengan ritual atau upacara untuk meminta kesuburan tanah. Upacara ini dilakukan supaya hasil pertanian warga melimpah-ruah. Karena terkait dengan kesuburan inilah, gerakan dalam tarian yang dilakukan oleh penari perempuan (ledhek) dengan penari laki-laki (pengibing) ini, mirip gerakan orang yang sedang bercinta. Tarian tersebut memang terlihat erotis, tapi saat itu tariannya tak lebih dari sekadar melambangkan kesuburan saja (Enanto, 2007).

Tradisi ronggeng dari Jawa ini memang diakui oleh maestro ronggeng pasaman masuk ke wilayah Pasaman pada masa penjajahan Belanda dulunya. Saat itu penari ronggeng dari Jawa juga didatangkan bersama para pekerja rodi untuk bekerja di perkebunan karet milik Belanda. Sementara itu, penari ronggeng didatangkan untuk menghibur orang-orang Belanda yang ada diperkebunan tersebut.

Ketika ronggeng ini kemudian menjadi salah satu seni tradisi yang terdapat di Pasaman (Minang), seni tradisi tersebut menjadi sebuah seni tradisi yang sangat berbeda dengan yang terdapat di Jawa. Ronggeng pasaman merupakan salah satu tradisi lisan yang menggabungkan keahlian berpantun dan menari dalam satu pertunjukan dengan diringi musik berirama Melayu. Pantun sebagai unsur 
penting dalam tradisi ini didendangkan atau dinyanyikan oleh seorang penampil 'wanita' atau "ronggeng" sambil berjoget mengikuti irama lagu. Dengan demikian, penyebutan kata 'ronggeng' mengacu pada dua pengertian, yaitu ronggeng sebagai satu bentuk seni pertunjukan dan 'ronggeng' sebagai sebutan untuk pelaku (penampil) 'wanita' yang ahli dalam berpantun.

Ronggeng pasaman sebagai sebuah seni tradisi mempunyai fungsi hiburan atau sebagai pelipur lara. Biasanya seni tradisi ini dipertunjukkan pada malam hari, mulai pukul sepuluh malam sampai pagi menjelang subuh (kira-kira pukul lima pagi). Tempat pertunjukan biasanya di lapangan terbuka atau di pentas yang dibuat khusus untuk pertunjukan dan dipertunjukkan dalam pesta perkawinan atau dalam acara peringatan keagamaan, seperti pada hari Raya Idul Fitri dan Idul Adha.

Pantun sebagai unsur utama atau unsur inti dari tradisi ronggeng pasaman. Jenis pantun yang dibawakan adalah pantun muda-mudi dan didendangkan atau dinyanyikan mengikuti irama lagu, seperti lagu "Cerai Kasih", "Kaparinyo", "Buah Sempaya", "Tari Payung", "Mainang", "Alah Sayang" "Sinambang" dan "Si Kambang Baruih". Dari beberapa irama lagu ini, irama lagu "Kaparinyo" lebih dominan di Simpang Empat, sedangkan irama lagu "Cerai Kasih" lebih dominan di Simpang Tonang. Pantun-pantun yang didendangkan atau dinyanyikan mengikuti irama-irama lagu tadi dilantunkan oleh 'ronggeng' dan penampil pria, sambil menari dan secara bergantian. Gerak tari yang mereka lakukan sesuai pula dengan irama lagu yang didendangkan.

Penampil (pemain) dalam pertunjukan ronggeng pasaman terdiri atas satu orang penampil 'wanita' atau "ronggeng", tiga orang atau lebih penampil pria, dan lima orang pemain musik. Dengan demikian, penampil (pemain) dalam ronggeng dapat dibagi tiga, yaitu penampil 'wanita' atau "ronggeng", penampil pria, dan pemain musik. Meskipun disebutkan ada penampil 'wanita' atau "ronggeng", namun dalam kenyataannya para penampil tersebut semuanya adalah laki-laki. Untuk penampil 'perempun', laki-laki tersebut didandani seperti perempuan yang memakai baju kurung dengan selendang².

Pertunjukan dimulai oleh lantunan musik berirama Melayu. Kemudian, penari 'perempuan' atau 'ronggeng' berdiri diiringi oleh penari laki-laki. Sambil menari, 'ronggeng' mendendangkan pantun, dan kemudian pantun itu dibalas oleh penari pria. Penari pria menari berpasangan dengan 'ronggeng' secara bergantian. Penari pria yang sedang berpasangan dengan 'ronggeng' inilah yang harus membalas pantun-pantun dari 'ronggeng'.

\section{Hibriditas dalam Tradisi Lisan Ronggeng Pasaman}

Sebagai sebuah seni tradisi yang sudah diakui sebagai seni tradisi Minangkabau, dalam pertunjukannya secara keseluruhan terlihat ada perpaduan pengaruh kebudayaan di dalamnya. Pertama adalah pengaruh kebudayaan Jawa. 2 Peran pengganti perempuan saat ini tidak lagi berlaku dalam pertunjukan ronggeng pasaman. 
Kata ronggeng sendiri tidak ada dalam kosakata bahasa Minang. Ketika tradisi ronggeng ini menjadi salah satu tradisi di Minang, pemakaian nama ronggeng itu sendiri sudah menggambarkan akulturasi antara seni tradisi Jawa dengan seni tradisi Minang. Konsep pertunjukan ronggeng di Jawa, yaitu berupa tarian yang ditarikan oleh beberapa orang wanita yang kemudian didekati oleh penari laki-laki sehingga tercipta tari berpasangan antara laki-laki dan perempuan. Tradisi ronggeng yang terdapat di Pasaman juga merupakan pertunjukan tari antara laki-laki dan 'perempuan' yang dalam hal ini tidak sama dengan di Jawa yang menonjolkan gerakan-gerakan sebagai simbol ritus kesuburan. Dalam tradisi ronggeng pasaman, tarian tersebut lebih kepada tarian gerak langkah kecil ke kiri dan ke kanan, serta ke depan dan ke belakang seirama dengan musik yang mengiringi pertunjukan tersebut. Yang lebih utama dari pertunjukan tersebut sebenarnya bukanlah tarian, namun berbalas pantun antara laki-laki dan perempuan yang menari berpasangan tersebut. Sehingga gerakan yang menjadi simbol kesuburan seperti dalam ronggeng di Jawa tidak ditemui dalam tradisi ronggeng pasaman.

Hal ini juga memperlihatkan perpaduan tradisi Jawa tersebut dengan adat istiadat serta kebiasaan di Minang yang menabukan pertunjukan seperti ronggeng di Jawa karena dasar adat Minang yang bersendikan kepada ajaran agama Islam. Dasarnya adalah pepatah adat Minang, adat basandi syarak, syarak basandi kitabullah (adat bersendi syarak, syarak bersendi kitabullah); syarak mangato, adat mamakai (syarak mengatakan, adat menggunakan).

Selain itu, dalam tradisi Minang perempuan juga dilarang untuk tampil dalam sebuah pertunjukan di muka umum ${ }^{3}$. Oleh karena itu, pertunjukan ronggeng pasaman yang sejatinya dilakukan oleh perempuan dengan laki-laki akhirnya dilakukan oleh laki-laki saja. Agar tetap terlihat ada perempuan, maka laki-laki tersebut ada yang didandani seperti perempuan.

Kedua, pengaruh dari tradisi Mandailing terlihat dari bahasa yang dituturkan oleh pemantun. Pantun dalam pertunjukan ronggeng pasaman secara umum dituturkan dalam bahasa Minangkabau dialek Pasaman. Selain itu, bahasa Minang dengan dialek Pasaman tersebut sebagian juga merupakan campuran bahasa Minangkabau dengan bahasa Mandailing yang telah menjadi dua bahasa dominan dalam masyarakat Pasaman (Amir, 2007:130).

Ketiga, tradisi berpantun itu sendiri merupakan salah satu tradisi khas Melayu. Di sini juga terlihat pengaruh dari budaya Melayu. Selain tradisi berpantun tersebut, alat musik pengiring pertunjukan adalah alat musik Melayu seperti kendang, biola, saksofon, akordion. Jadi musik pengiringnya bukanlah musik tradisional Minang dengan alat musiknya talempong, pupuik, atau sarunai. Meskipun alat musik pengiringnya bukan alat musik tradisional Minangkabau, namun irama lagu yang digunakan adalah irama lagu tradisional Minang seperti "Mainang", "Kapariyo", dan "Tari Payung” yang jika ditinjau lagi tetap ada nuansa Melayunya.

3 Perempuan dulunya tabu untuk tampil di depan umum dalam sebuah pertunjukan di Minangkabau. Adanya penari atau penampil perempuan dalam sebuah pertunjukan baru muncul belakangan ini dan hal itu sudah tidak tabu lagi seperti dulu. 


\section{Simpulan}

Pasaman merupakan salah satu wilayah adinistratif (Kabupaten) yang terdapat di provinsi Sumatera Barat. Persisnya daerah Pasaman ini berbatasan di sebelah utara dengan provinsi Sumatera Utara. Daerah ini didiami oleh tiga etnis dominan, yaitu Minang, Jawa, dan Mandailing.

Masing-masing etnis tersebut dapat dikatakan telah mengalami diaspora. Suku Minang yang ada di wilayah tersebut juga dianggap telah merantau karena wilayah Pasaman bukanlah wilayah pusat kebudayaan Minangkabau. Orang Jawa yang ada di daerah Pasaman juga telah mengalami migrasi sejak zaman Belanda ketika saat itu tenaga mereka dibutuhkan untuk bekerja di perkebunan-perkebunan karet Pasaman. Orang Mandailing sendiri juga telah lama ada di daerah Pasaman karena dalam sejarah kerajaan Mandahiling, daerah Pasaman juga merupakan daerah perluasan kerajaan mereka (bukan pusat kebudayaan suku Mandailing). Ketiga etnis yang sudah lama mendiami Pasaman ini pun telah hidup hingga dua sampai tiga generasi. Masing-masing tetap ada kaitannya atau mengacu pada tradisi dan budaya dari tempat asalnya untuk mereka gunakan di tempat barunya tersebut (Pasaman). Akibatnya muncullah berbagai produk budaya hibrid yang salah satunya dapat dilihat pada tradisi lisan ronggeng pasaman.

Ronggeng pasaman adalah tradisi lisan yang merupakan gabungan dari pertujukan tari, pantun, dan musik. Hibriditas dari tradisi ini pertama terlihat dari namanya yang mengambil nama dari tradisi ronggeng di Jawa. Konsep ronggeng di Jawa yang merupakan tarian berpasangan antara laki-laki dan perempuan juga terdapat dalam ronggeng pasaman, namun gerakannya tidak sama dengan tarian ronggeng di Jawa.

Kedua, larangan bagi perempuan untuk tampil di depan umum dalam sebuah pertunjukan tradisi di Minang juga diadopsi oleh pertunjukan ronggeng pasaman sehingga yang menari secara keseluruhan dapat dikatakan adalah laki-laki. Untuk penari perempuan, laki-laki tersebut didandani seperti perempuan yang memakai baju kurung atau kebaya dengan selendang di kepala.

Ketiga, tradisi Melayu yang khas yaitu berpantun serta alat musik pengiring (seperti biola, akordion, dan sebagainya) terdapat dalam tradisi ronggeng ini. Pantun dan musik Melayu ini justru menjadi salah satu bagian yang dominan dari pertunjukan (bukan tarian seperti halnya di Jawa).

Keempat, pengaruh budaya Mandailing dapat dilihat dari tuturan yang digunakan dalam pantun mereka. Bahasanya adalah bahasa Minang dengan logat Pasaman. Dalam bahasa Minang logat Pasaman itu juga terdapat beberapa kosakata Mandailing yang berbeda dengan kosakata bahasa Minang.

\section{Daftar Acuan}

Amir, Adriyetti,dkk. Pemetaan Sastra Lisan Minangkabau. Padang: Andalas University Press, 2006 
Amir, M.S. Adat Minangkabau: Pola dan Tujuan Hidup Orang Minang. Jakarta: PT Mutiara Sumber Widya, 2003.

Budianta, Melani. 2007. "Aspek Lintas Budaya dalam Wacana Multikultur". Makalah untuk Seminar Kajian Wacana dalam Konteks Multikutur dan Perspektif Multidisiplin. Depok: FIB UI.

Ernanto, Didit. "Endang Caturwati Mengangkat Citra Ronggeng". http://www. sinarharapan.co.id diunduh pada hari Rabu, 17 November 2008 pukul 14.25 WIB.

Hall, Stuart. 1990. "Cultural Identity and Diaspora" dalam Identity, Community, Culture, and Difference. London: Lawrence K. Wishart.

Hamka. Islam dan Adat Minangkabau. Jakarta: Pustaka Panjimas, 1984.

Lubis, Pengaduan. "Mandailing dalam Lintasan Sejarah". http://www.mandailing. org, diunduh Rabu, 17 November 2008 pukul 15.15 WIB.

Parekh, Bhikhu. "National Culture and Multiculturalism."

Samad, Duski, dkk. Ensiklopedia Minangkabau. Jakarta: PT Rumpun Dian Nugraha dan Gebu Minang, 2002.

www.depdagri.go.id, diunduh pada hari Rabu, 17 November 2008 pukul 14.25 WIB. Zuriati. "Ronggeng Pasaman". http://zuriati.wordpress.com. Diunduh Rabu, 17 November 2008 pukul 11.00 WIB. 
